\title{
Attributabiliity of death to pneumoconiosis in beneficiaries
}

\author{
R. L. S A D L E R \\ Pneumoconiosis Medical Panel, Swansea
}

\begin{abstract}
Sadler, R. L. (1974). Thorax, 29, 699-702. Attributability of death to pneumoconiosis in beneficiaries. Coal workers and slate workers who were receiving in 1965 industrial disability benefit for pneumoconiosis were grouped according to the radiological extent of their disease and their disability assessment. They were followed up for $7 \cdot 5$ years. Standard mortality rates, and from these the percentage of all deaths which can be attributed to pneumoconiosis, were assessed. About $10 \%$ of the deaths in the coal workers and about $40 \%$ of those in the slate workers were found to be accelerated by their pneumoconiosis, the proportion varying directly with the radiological extent of the disease and with the disability assessment at the beginning of the survey.
\end{abstract}

The subjects of this investigation were 1,863 beneficiaries with coal workers' pneumoconiosis from industrial South Wales and 291 with slate workers' silicosis from rural North Wales, all of whom had attended the Swansea Pneumoconiosis Medical Panel for initial or reassessment examinations during 1965. Those examined more than once during the year were counted only at their first visit. Medical boards assess disability from pneumoconiosis in gradations of $10 \%$ and examine most beneficiaries at intervals throughout their lives.

Both the coal workers and slate workers were grouped according to their radiological classification (International Labour Office, 1970) as follows: (a) simple pneumoconiosis; (b) complicated pneumoconiosis with A opacities; (c) complicated pneumoconiosis with B or C opacities; $(d)$ pneumoconiosis accompanied by pulmonary tuberculosis. The effects of tuberculosis found in the presence of pneumoconiosis are taken fully into account for benefit purposes.

The examinees had attended in equal numbers on working days throughout 1965 so that by 1 January 1966 the average period of their follow-up was six months and by 1 January 1973, when the survey ended, seven and a half years. To comply with the usage in the Registrar General's tables (in which mortality rates are based on ages at mid-year) their ages were taken to be those at 1 July 1965 . No subject was lost sight of.

Numbers of expected deaths are calculated from the Registrar General's abridged life table for England and Wales, based on deaths in 1968-70, in which figures for every fifth year of age are given (Registrar General's Quarterly Return for England and Wales, 1971). Deaths expected in 7.5 years are calculated after grouping the subjects into five-year groups centred on the ages used in the life table.

The logarithms of death rates for England and Wales plotted graphically fall on a straight line from which death rates at each age can be derived by interpolation. The standard mortality rates (SMR) calculated from expected death rates obtained from yearly rates, however, differ from those obtained by using ages in five-year groups by less than $2 \%$; and it is considered that use of the grouped ages gives sufficient accuracy for the present purpose.

In Table I are shown the SMRs of coal and slate workers according to radiological groups, and in Table III according to their disability assessments in 1965. The distribution of disability assessments is compared in Table II with that of all pneumoconiosis beneficiaries in the United Kingdom in the same year (Ministry of Power, 1967).

\section{DISCUSSION}

Table I shows that the SMRs of the slate workers exceed those of the coal workers in all but one of the radiological groups. The small group with tuberculosis is the exceptional one, a finding that probably owes something to the difficulties in diagnosing pulmonary tuberculosis where massive fibrosis is also present. Although the two diseases are so commonly associated, characteristic histological changes in such cases are often entirely lacking, and even 
T A B L E I

DEATHS AMONG BENEFICIARIES IN 7.5 YEARS

\begin{tabular}{|c|c|c|c|c|c|}
\hline \multirow[t]{2}{*}{ Type of Pneumoconiosis } & \multirow[t]{2}{*}{ At Risk } & \multicolumn{2}{|c|}{ Deaths } & \multirow[t]{2}{*}{ SMR } & \multirow{2}{*}{$\begin{array}{l}\text { Deaths Expected due to } \\
\text { Pneumoconiosis } \\
\text { ( } \% \text { of reported deaths) }\end{array}$} \\
\hline & & Expected & Reported & & \\
\hline $\begin{array}{l}\text { Coal Workers } \\
\text { Simple } \\
\text { Category A } \\
\text { Categories B and C } \\
\text { With tuberculosis } \\
\text { All beneficiaries }\end{array}$ & $\begin{array}{r}1,049 \\
436 \\
346 \\
32 \\
1,863\end{array}$ & $\begin{array}{r}189 \cdot 2 \\
98 \cdot 7 \\
80 \cdot 5 \\
5 \cdot 0 \\
373 \cdot 4\end{array}$ & $\begin{array}{r}223 \\
113 \\
135 \\
16 \\
487\end{array}$ & $\begin{array}{l}117 \cdot 9 \\
114 \cdot 5 \\
167 \cdot 7 \\
320 \cdot 0 \\
130 \cdot 4\end{array}$ & $\begin{array}{r}0 \\
0 \\
29 \cdot 7 \\
63 \cdot 2 \\
9 \cdot 6\end{array}$ \\
\hline $\begin{array}{l}\text { Slate Workers } \\
\text { Simple } \\
\text { Category A } \\
\text { Categories B and C } \\
\text { With tuberculosis } \\
\text { All beneficiaries }\end{array}$ & $\begin{array}{r}115 \\
62 \\
71 \\
43 \\
291\end{array}$ & $\begin{array}{l}28 \cdot 7 \\
21 \cdot 6 \\
19 \cdot 3 \\
10 \cdot 4 \\
80 \cdot 0\end{array}$ & $\begin{array}{l}55 \\
35 \\
42 \\
24 \\
156\end{array}$ & $\begin{array}{l}191 \cdot 6 \\
162 \cdot 0 \\
217 \cdot 6 \\
230 \cdot 8 \\
195 \cdot 0\end{array}$ & $\begin{array}{l}38 \cdot 4 \\
27 \cdot 2 \\
45 \cdot 8 \\
48 \cdot 9 \\
39 \cdot 5\end{array}$ \\
\hline
\end{tabular}

T A B L E I I

PERCENTAGE DISTRIBUTION OF DISABILITY ASSESSMENTS IN 1965

\begin{tabular}{c|c|c|c}
\hline $\begin{array}{c}\text { Disability } \\
\text { Assessment } \\
\text { (percentage) }\end{array}$ & $\begin{array}{c}\text { UK All } \\
\text { Industries } \\
(\mathrm{n}=47,835)\end{array}$ & $\begin{array}{c}\text { S. Wales } \\
\text { Coal Workers } \\
(\mathrm{n}=1,863)\end{array}$ & $\begin{array}{c}\text { N. Wales } \\
\text { Slate Workers } \\
(\mathrm{n}=291)\end{array}$ \\
\hline $10-30$ & $80 \cdot 2$ & $82 \cdot 6$ & $54 \cdot 0$ \\
$40-60$ & $13 \cdot 1$ & $11 \cdot 7$ & 19.9 \\
$70-90$ & $2 \cdot 8$ & $2 \cdot 6$ & $8 \cdot 3$ \\
100 & 3.9 & $3 \cdot 2$ & 17.9 \\
\hline All & $100 \cdot 0$ & $100 \cdot 1$ & $100 \cdot 1$ \\
\hline
\end{tabular}

cultural and animal inoculation techniques may fail to prove the presence of tubercle bacilli suspected on clinical grounds (Spencer, 1968).

In coal workers with radiological A opacities the SMR is similar to that of miners with simple pneumoconiosis, a finding also reported by Cochrane, Moore, and Thomas (1961) and by Cochrane (1973). In the slate workers of this study those with A opacities have a lower SMR than have those with simple pneumoconiosis.
In the Rhondda Fach SMRs have been computed after six years (Cochrane, Carpenter, Moore, and $z$ Thomas, 1964) and after 20 years follow-up (Cochrane, 1973). These studies show that the mortality rate in coal workers with complicated pneumoconiosis is greater than in those with simple pneumoconiosis, but that in those with simple pneumoconiosis the SMR is no higher than in. miners with no pneumoconiosis.

There is evidence (Lyons, Ryder, Campbell, and Gough, 1972) that almost all coal workers in South Wales who are suffering from pneumoconiosis are known to the pneumoconiosis medical panels, and it is reasonable to assume that the subjects of this study with simple pneumoconiosis have a mortality rate similar to that of the population of coal workers with simple pneumoconiosis, or without pneumoconiosis, in the same area.

Cochrane (1962) found no association between the attack rate of progressive massive fibrosis (PMF) and age, energy expenditure at work, smoking habits, body type, and exogenous and endogenous tuber-

T A B L E I I I

DEATHS AMONG BENEFICIARIES IN 7.5 YEARS

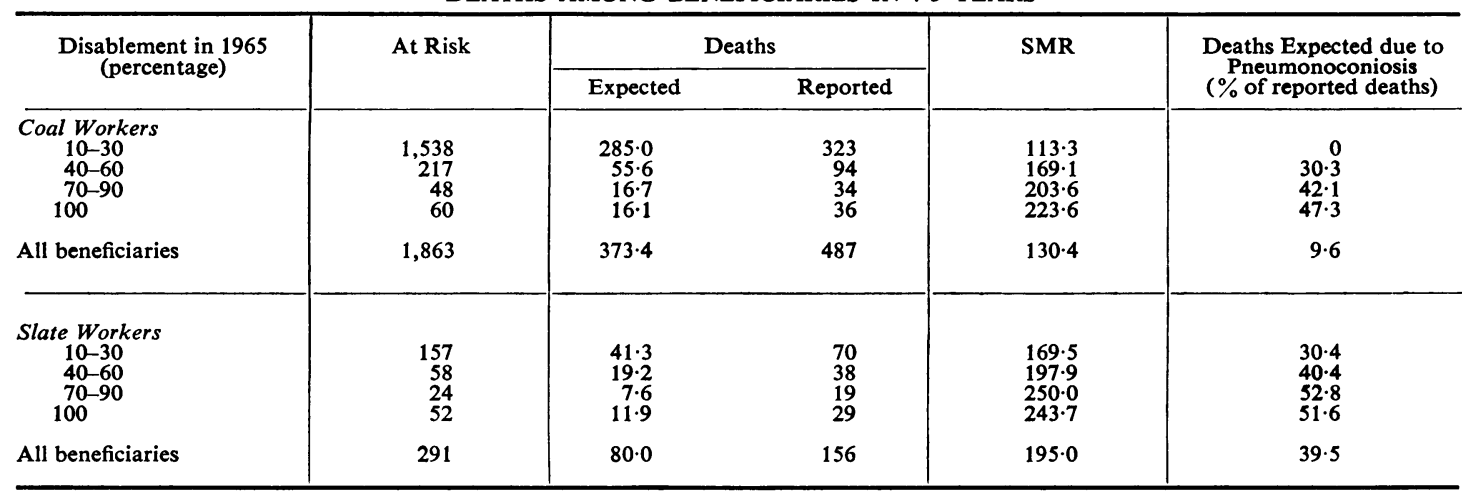


culous infection; and he concluded that the only factor relating to the attack rate of PMF was the category of simple pneumoconiosis. It appears from this study that the higher mortality associated with complicated pneumoconiosis is due to the PMF per $s e$ and is not due to the miners with complicated pneumoconiosis being in other respects a selected group.

The respective SMRs (Table I) of simple and complicated pneumoconiosis are approximately 118 and 168. One implication of this finding is that if a large group of coal workers with simple pneumoconiosis were followed up until exactly 118 deaths had occurred, in a second group of coal workers with complicated pneumoconiosis matched for number and ages and followed up the same length of time 168 deaths would have occurred.

In these circumstances the additional 50 deaths in the second group would be attributable to the effects of their complicated pneumoconiosis; and the proportion of all deaths in the second group attributable to their industrial disease would be $50 / 168$ or $30 \%$. Thus a general formula for assessing the proportion of attributable deaths in a particular group of subjects with complicated pneumoconiosis would be: $\frac{S M R_{c}-S M R_{s}}{S M R_{c}}$, where $S M R_{c}$ is the SMR of the group under consideration with complicated pneumoconiosis and $\mathrm{SMR}_{\mathrm{s}}$ that of all subjects from the same environment with simple pneumoconiosis.

Cochrane, Carpenter, and Moore (1959) used a similar method. They considered that in their group with advanced complicated pneumoconiosis the excess deaths over those expected for all males could be attributed to the industrial disease.

The accuracy of these estimations may be limited by unknown factors. Some of the deaths, for instance, which were 'expected' to occur and did occur within the period of follow-up may have been accelerated so as to take place at an earlier date within this period; such accelerated deaths would not be reflected in the SMRs in the tables, giving an underestimation of those attributable. The SMRs determined after brief periods of follow-up however would be affected, if they occurred, by such accelerated deaths. Deaths 'expected' to occur after 1972 could be accelerated similarly so that they took place within the follow-up period; and these deaths then would add to the 'unexpected' deaths occurring in the follow-up period and raise the SMR.

Not assessed in this study were the effects of the subjects' occupations within the coalmining industry. In accordance with the fittest men performing the most arduous work there are considerable differences in the SMRs of coalface workers, other underground workers, and those employed on the surface (Liddell, 1973).

In the absence of information about the mortality rate of slate workers without pneumoconiosis we have taken their SMR as being that of all surface workers in mines and quarries (118) in the Registrar General's occupational mortality tables (Registrar General's Decennial Supplement, England and Wales, 1961 (1971). The SMR of the slate workers with simple pneumoconiosis in the present study is considerably higher than this.

The proportion of deaths attributable to pneumoconiosis (simple or complicated) is the fraction: SMR - 118

SMR , the SMR being that of the group of slate workers under consideration.

The final column in Table I shows the percentage of total deaths which these calculations show to be attributable to pneumoconiosis. It appears that about $10 \%$ of all deaths in coal workers and about $40 \%$ of those in slate workers are caused or materially accelerated by their industrial disease.

In those with advanced complicated pneumoconiosis (B or C opacities) about half the deaths in slate workers and about one-third of those in coal workers are attributable to their pneumoconiosis; and in the small group of coal workers whose pneumoconiosis was accompanied by tuberculosis about two-thirds of all deaths are due to their industrial disease. In the similar calculation by Cochrane et al. (1959) it was found that among coal workers with advanced complicated pneumoconiosis $42 \%$ of 192 deaths were attributable to the industrial disease.

In Table III mortality rates and disability assessments are related. About half of all deaths in coal and slate workers whose disability in life was at least $70 \%$ appear attributable to their pneumoconiosis.

The distribution of the disability assessments of the coal workers in this study (Table II) is similar to that found in all pneumoconiosis beneficiaries in the United Kingdom in 1965, but a larger proportion of the slate workers have assessments greater than $30 \%$.

For the purpose of industrial death benefit the decision whether or not a death is due to pneumoconiosis is made by the lay statutory authorities (Ministry of Social Security, 1967). These authorities take into account all the available evidence, including the pathologist's report, the opinion of two doctors of the pneumoconiosis medical panel who make their own independent examination of the lungs and heart, and any reports by the deceased's own doctor on the terminal illness and mode of death. In a sizable collection of death cases so considered the validity of the medical opinions could be tested with the findings in the final columns of Tables I and III. 
For permission to make use of the panel records I am indebted to Dr. J. A G. Carmichael, Chief Medical Adviser, Department of Health and Social Security; and I am duly appreciative of the most helpful advice given by Mr. E. J. Brady and colleagues of the Statistical Branch and of the enthusiastic assistance of our clerical officers at Swansea.

\section{REFERENCES}

Cochrane, A. L. (1962). The attack rate of progressive massive fibrosis. British Journal of Industrial Medicine, 19, 52.

(1973). Relation between radiographic categories of coalworkers' pneumoconiosis and expectation of life. British Medical Journal, 2, 532.

- Carpenter, R. G., and Moore, F. (1959). Investigation into the working of the 'death benefit' for coalworkers' pneumoconiosis. British Journal of Preventive and Social Medicine, 13, 128.

$\longrightarrow,-, \ldots$, and Thomas, J. (1964). The mortality of miners and ex-miners in the Rhondda Fach. British Journal of Industrial Medicine, 21, 38.

, Moore, F., and Thomas, J. (1961). The prognostic value of radiological classification in cases of progressive massive fibrosis. Tubercle, 42, 64.
International Labour Office (1970). International Classifi cation of Radiographs of Pneumoconiosis. Occupational Safety and Health Series, 22. Internationalo Labour Office, Geneva.

Liddell, F. D. K. (1973). Mortality of British coal miners in 1961. British Journal of Industrial Medicine, 30, 15.0

Lyons, J. P., Ryder, R., Campbell, H., and Gough, J. ${ }^{\infty}$ (1972). Pulmonary disability in coalworkers' pneumo- $\vec{\circ}$ coniosis. British Medical Journal, 1, 713.

Ministry of Power (1967). Digest of Pneumoconiosis $\vec{\omega}$ Statistics. HMSO, London.

Ministry of Social Security (1967). Pneumoconiosis andx Allied Occupational Chest Diseases. HMSO, London. तु

Registrar General's Decennial Supplement, Englandos and Wales, 1961 (1971). Occupational Mortalityo Tables, 135. HMSO, London.

Registrar General's Quarterly Return for England and음 Wales (1971). 490. HMSO, London.

Spencer, H. (1968). Pathology of the Lung, 2nd ed. Perga-Z mon Press, London.

Requests for reprints to: Dr. R. L. Sadler, Pneumoconiosis Medical Panel, Grove House, 3 Grove Place, $\vec{c}$ Alexandra Road, Swansea SA1 5DF. 